Article

\title{
Two-Phase Interleaved Boost Converter with ZVT Turn-On for Main Switches and ZCS Turn-Off for Auxiliary Switches Based on One Resonant Loop
}

\author{
Yeu-Torng Yau ${ }^{1}$, Kuo-Ing Hwu ${ }^{2, * \mathbb{D}}$ and Wen-Zhuang Jiang ${ }^{3}$ \\ 1 Department of Ph.D. Program, Prospective Technology of Electrical Engineering and Computer Science, \\ and Department of Electrical Engineering, National Chin-Yi University of Technology, No.57, Section 2, \\ Zhongshan Rd., Taiping Dist., Taichung 41170, Taiwan; Pabloyau@ncut.edu.tw \\ 2 Department of Electrical Engineering, National Taipei University of Technology, 1, Section 3, \\ Zhongxiao E. Rd., Taipei 10608, Taiwan \\ 3 Chicony Power Technology Co., Ltd., Sanchong, New Taipei 208, Taiwan; \\ Vincent_Jiang@chiconypower.com.tw \\ * Correspondence: eaglehwu@ntut.edu.tw; Tel.: +886-2-2771-2171 (ext. 2159)
}

Received: 12 May 2020; Accepted: 1 June 2020; Published: 3 June 2020

\begin{abstract}
A two-phase interleaved boost converter with soft switching is proposed herein. By means of only one auxiliary circuit with two auxiliary switches having zero-current switching (ZCS) turn-on, two main switches are switched on with zero-voltage transition (ZVT) to enhance the overall efficiency. Moreover, a current-balancing circuit with a no current-balancing bus is utilized to render the load current extracted from the two phases as even as possible, so that the system stability is upgraded. In such a study, this converter, having the input of $24 \mathrm{~V} \pm 10 \%$ and the rated output of $36 \mathrm{~V} / 6 \mathrm{~A}$, was employed to demonstrate the effectiveness of such a converter by experiment.
\end{abstract}

Keywords: boost converter; current balancing; two-phase; interleaved control; ZVT; ZCS

\section{Introduction}

As well known, the switching power supply is widely used today. This is because of its small volume, high efficiency, etc. However, it has some disadvantages due to its hard switching, such as high switching loss, large voltage/current stress and strong electromagnetic interference.

To overcome the demerits mentioned above, the quasi-resonant converter (QRC) [1-6] has been investigated since 1980, mainly on the condition that the voltage/current waveform is sinusoidal. This converter contains the resonant inductor in a series with the switch or the diode, and hence resonates with the switch parasitic capacitor or the diode parasitic capacitor so that the zero-voltage switching (ZVS) during the turn-on period or the zero-current switching (ZCS) during the turn-off period can be realized. However, this inductor locates on the path of the main power stage such that the high voltage/current on/in the switch or diode will occur and hence the circulation current is unavoidable, thereby creating a large conduction loss. Moreover, the resonant energy comes from the input and the load such that the soft switching can be achieved only for some input voltage range as well as some load range.

To overcome the demerits of QRCs, a resonant network paralleled with the main power stage path was developed. Some derived structures were presented, such as active clamp [7-21], zero-voltage transition (ZVT) and zero-current transition (ZCT) [22-33]. The last two structures use resonant networks, which will make the main switch have ZVS and ZCS according to the auxiliary switch. Furthermore, the voltage on the switch and the current in the switch are of sinusoidal form. By doing so, the voltage stress and current stress for the switch are effectively alleviated, causing the circulation 
current to be small and hence the unavoidable conduction loss to be reduced. Moreover, the required resonant energy is not all determined by the input voltage and output load. Accordingly, in design of the resonant parameters for soft switching all over the range of input voltage and output load, only the minimum input voltage and the maximum output load were considered.

On the other hand, to increase the output current as well as to upgrade the corresponding overall efficiency, the multiphase converter along with interleaved control are commonly utilized. Since the AC components of the inductor currents for multiple phases are cancelled with each other to some extent, not only is the output current ripple thereby decreased but also the frequency of the output current ripple is increased. Accordingly, not only will the design of the required filter be easier, but the corresponding size will also be smaller. Generally, the total loss generated from multiple phases will be smaller than that generated from one phase. Furthermore, the soft switching multiphase converter is proposed so that the overall efficiency is further upgraded. The literature [34-37] takes multiple phases with the accompanying number of auxiliary resonance circuits, thereby resulting in increasing the number of components and hence increasing not only the conduction loss but also the cost. In the literature [36], the two-phase converter utilizes the same auxiliary resonant circuit. However, only the ZVS is employed so that the improvement in efficiency is restricted. In the literature [37], a two-phase converter adopts one snubber circuit to force the main switches to realize soft switching. Nevertheless, the resonant inductor is put on the power path, thus increasing the conduction loss. In addition, since there are differences in component features and line impedance between the two phases, the current-balancing control will be required. Regarding current balance, there are two types of current-balancing control strategies. One method is passive; the other method is active. The former adopts differential-mode transformers or capacitors or both to do current balance [38-41], while the latter consists of current regulators and sensors to do current balance [42-46].

Accordingly, only one resonant circuit, which is comprised of relatively few elements as compared with [47] is presented and imposed on a two-phase interleaved boost converter to force two main switches to have ZVT turn-on and two auxiliary switches to have ZCS turn-off. Moreover, as the switches operate under soft switching, the output current ripple is not affected such that the life of the capacitor can be prolonged. As for the current balance, a simple method, based on digital control with no current-balancing bus, is proposed to render the load current evenly distributed between the two phases.

\section{Proposed Converter}

Figure 1 shows the proposed converter containing a traditional two-phase boost converter with the parasitic diodes $D_{S 1}$ and $D_{S 2}$ and parasitic capacitors $C_{S 1}$ and $C_{S 2}$ for the main switches $S_{1}$ and $S_{2}$, respectively, the output didoes $D_{1}$ and $D_{2}$, and one output capacitor $C_{0}$, along with a resonant circuit, which is composed of only one resonant inductor $L_{r}$, only one resonant capacitor $C_{r}$, one resonant diode $D_{r}$, and two auxiliary switches $S_{a}$ and $S_{b}$ with parasitic diodes $D_{S a}$ and $D_{S b}$ and parasitic capacitors $C_{S a}$ and $C_{S b}$, respectively. Moreover, the output resistor is indicated by $R$.

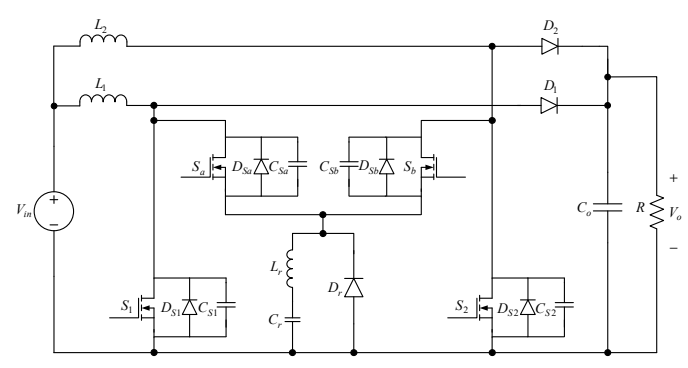

Figure 1. Proposed circuit. 


\section{Operation Behavior}

Before tackling this section, there are some assumptions and symbols to be given as below: (i) all the elements are viewed as ideal except the parasitic diodes and capacitors for the main switches and auxiliary switches; (ii) the input inductors can be regarded as current sources represented by $I_{L 1}$ and $I_{L 2}$; (iii) the output capacitor can be viewed as a voltage source $V_{o}$; (iv) this converter operates in the continuous current mode (CCM); (v) the gate-driving signals for the switches $S_{1}, S_{2}, S_{a}$ and $S_{b}$ are denoted by $v_{g 1}, v_{g 2}, v_{g a}$ and $v_{g b}$, respectively; (vi) the voltages across the switches $S_{1}, S_{2}, S_{a}$ and $S_{b}$ are signified by $v_{S 1}, v_{S 2}, v_{S a}$ and $v_{S b}$, respectively; (vii) the currents flowing through the switches $S_{1}, S_{2}$, $S_{a}$ and $S_{b}$ are represented by $i_{S 1}, i_{S 2}, i_{S a}$ and $i_{S b}$, respectively; (viii) the currents flowing through $D_{1}$, $D_{2}$ and $D_{r}$ are indicated by $i_{D 1}, i_{D 2}$ and $i_{D r}$, respectively; (ix) the current flowing through $L_{r}$ and the voltage across $C_{r}$ are denoted by $i_{L r}$ and $v_{C r}$, respectively.

According to the aforementioned assumptions and symbols, the converter in Figure 2 is an equivalent for that in Figure 1. In Figure 3, there are sixteen operation modes in this circuit. Since such a converter is controlled by interleave, namely, the gate-driving signal $v_{g 2}$ shifted by 180 degrees from the gate-driving signal $v_{g 1}$, the behavior of the first eight operation modes is identical to that of the last eight operation modes. Hence, only the first eight operation modes are illustrated.

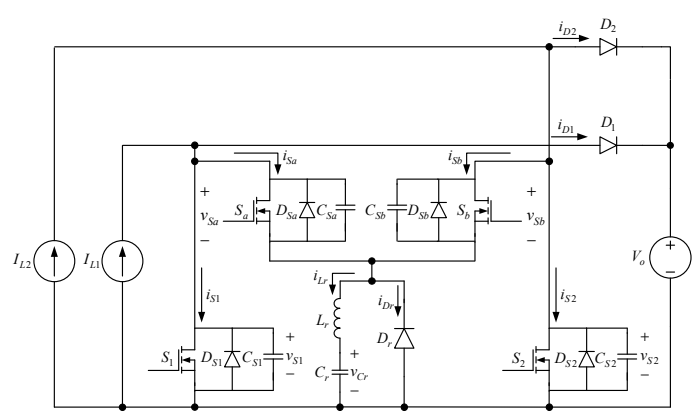

Figure 2. Equivalent circuit.

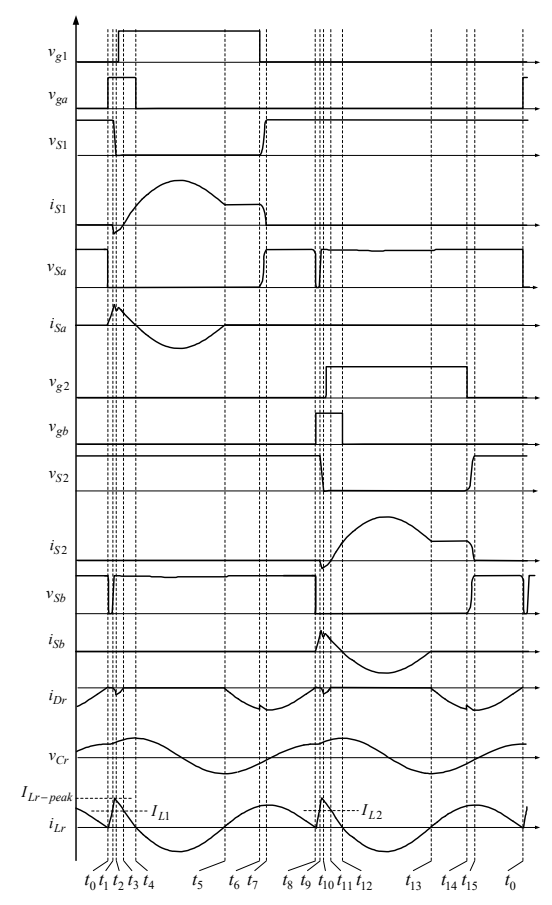

Figure 3. Illustrated waveforms. 
Mode 1: $\left[\boldsymbol{t}_{0} \leq \boldsymbol{t} \leq \boldsymbol{t}_{1}\right]$. As in Figure 4, the auxiliary switch $S_{a}$ is switched on at the instant $t_{0}$. Since the output diodes $D_{1}$ and $D_{2}$ are also switched on, thereby making the parasitic capacitor of $S_{b}$, called $C s_{b}$, abruptly discharged to zero. Meanwhile, the output voltage $V_{o}$ was imposed on the resonant inductor $L_{r}$ and the resonant capacitor $C_{r}$, thereby making $L_{r}$ and $C_{r}$ resonate. Moreover, the current $i_{S a}$ is equal to $i_{L r}$ and both are increasing, but the current $i_{D 1}$ begins to fall. As soon as $i_{L r}$ is equal to $I_{L 1}$, namely $i_{L r}\left(t_{1}\right)=I_{L 1}$, this mode ends. During such a mode, the accompanying equations are described as below:

$$
\left\{\begin{array}{l}
i_{L r}(t)=\frac{\left(V_{o}-v_{C r}\left(t_{0}\right)\right)}{Z_{1}} \sin \left(\omega_{1}\left(t-t_{0}\right)\right)+i_{L r}\left(t_{0}\right) \cos \left(\omega_{1}\left(t-t_{0}\right)\right) \\
v_{C r}(t)=V_{o}-\left(V_{o}-v_{C r}\left(t_{0}\right)\right) \cos \left(\omega_{1}\left(t-t_{0}\right)\right)+i_{L r}\left(t_{0}\right) Z_{1} \sin \left(\omega_{1}\left(t-t_{0}\right)\right)
\end{array}\right.
$$

where

$$
\omega_{1}=\sqrt{\frac{1}{L_{r} C_{r}}} \text { and } Z_{1}=\sqrt{\frac{L_{r}}{C_{r}}}
$$

At the instant $t_{0}, i_{L r}\left(t_{0}\right)$ is close to zero and $v_{C r}\left(t_{0}\right)$ is much smaller than $V_{o}$, so the expression of the current $i_{L r}$ from Equation (1) can be approximately represented by

$$
i_{L r}(t)=\frac{V_{o}}{Z_{1}} \sin \left(\omega_{1}\left(t-t_{0}\right)\right)
$$

From Equation (3), the elapsed time for this mode can be obtained to be

$$
\left(t_{1}-t_{0}\right)=\frac{1}{\omega_{1}} \sin ^{-1}\left[\frac{I_{L 1} Z_{1}}{V_{o}}\right]
$$

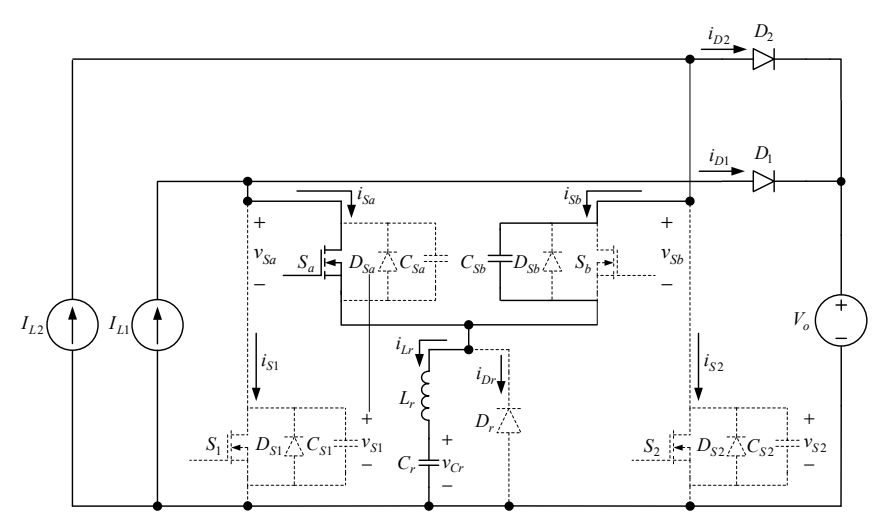

Figure 4. Current path in mode 1.

Mode 2: $\left[t_{1} \leq t \leq t_{2}\right]$. As in Figure 5, the output diode $D_{1}$ is switched off. Meanwhile, the current $I_{L 2}$ charges the parasitic capacitor of the auxiliary switch $S_{b}$, called $C_{S b}$, to the output voltage $V_{o}$ abruptly, while the resonant inductor $L_{r}$ resonates with the resonant capacitor $C_{r}$ in series with the parasitic capacitor of the main switch $S_{1}$, called $C_{S 1}$. Since the current $i_{S a}$ is equal to $i_{L r}$, the current $I_{L 1}$ is the sum of the currents of $i_{L r}$ and $i_{S 1}$. Therefore, $I_{L r}$ will force $C_{S 1}$ to discharge, thereby causing the voltage across $S_{1}$, called $v_{S 1}$, to be dropped. As soon as $v_{S 1}$ is zero, this mode ends. During such a mode, the accompanying equations are described as below:

$$
\left\{\begin{aligned}
i_{L r}(t)= & \frac{V_{1}}{Z_{2}} \sin \left(\omega_{2}\left(t-t_{1}\right)\right)+I_{1} \cos \left(\omega_{2}\left(t-t_{1}\right)\right)-I_{1}+i_{L r}\left(t_{1}\right) \\
v_{S 1}(t)= & \frac{C}{C_{S 1}}\left(V_{1} \cos \left(\omega_{2}\left(t-t_{1}\right)\right)-I_{1} Z_{2} \sin \left(\omega_{2}\left(t-t_{1}\right)\right)-V_{1}\right)+ \\
& \frac{I_{L 1}}{C_{r}+C_{S 1}}\left(t-t_{1}\right)+V_{o} \\
v_{C r}(t)= & -\frac{C}{C_{r}}\left(V_{1} \cos \left(\omega_{2}\left(t-t_{1}\right)\right)-I_{1} Z_{2} \sin \left(\omega_{2}\left(t-t_{1}\right)\right)-V_{1}\right)+ \\
& \frac{I_{L 1}}{C_{r}+C_{S 1}}\left(t-t_{1}\right)+v_{C r}\left(t_{1}\right)
\end{aligned}\right.
$$


where

$$
\begin{aligned}
& C=\frac{C_{r} C_{S 1}}{C_{r}+C_{S 1}}, \omega_{2}=\sqrt{\frac{1}{L_{r} C}}=\sqrt{\frac{C_{r}+C_{S 1}}{L_{r} C_{r} C_{S 1}}} \\
& Z_{2}=\sqrt{\frac{L_{r}}{C}}=\sqrt{\frac{L_{r}\left(C_{S 1}+C_{r}\right)}{C_{r} C_{S 1}}} \\
& V_{1}=V_{o}-v_{C r}\left(t_{1}\right), I_{1}=i_{L r}\left(t_{1}\right)-\frac{C}{C_{S 1}} I_{L 1}
\end{aligned}
$$

As the voltage $v_{S 1}$ is identical to the voltage $v_{C r}$, the resonant current $i_{L r}$, which flows through the auxiliary switch $S_{a}$, will be a maximum value, called $I_{\text {Lr-peak }}$, which can be expressed as

$$
I_{\text {Lr-peak }}=\frac{\sqrt{V_{1}^{2}+\left(I_{1} Z_{2}\right)^{2}}}{Z_{2}}+\frac{C}{C_{S 1}} I_{L 1}
$$

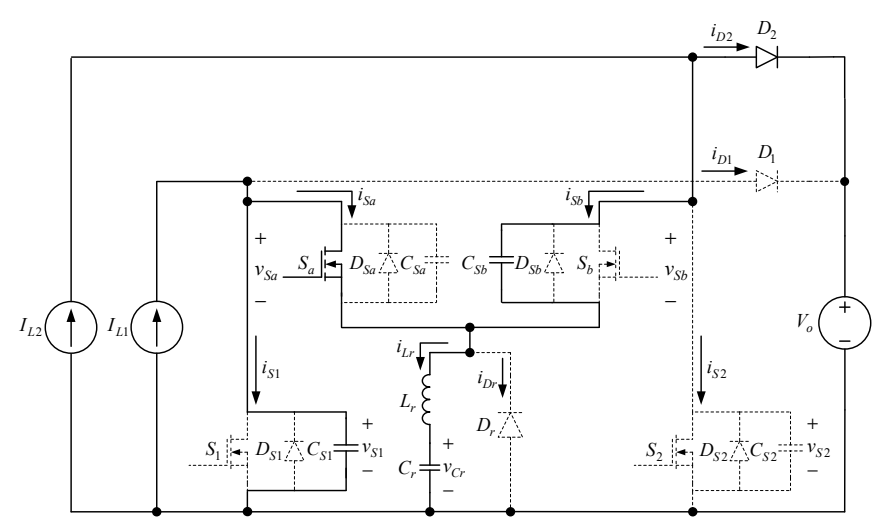

Figure 5. Current path in mode 2.

Mode 3: $\left[\boldsymbol{t}_{2} \leq \boldsymbol{t} \leq \boldsymbol{t}_{3}\right]$. As in Figure 6, the voltage across $S_{1}$, called $v_{S 1}$, is zero due to the parasitic diode of the switch $S_{1}$, called $D_{S 1}$, conducting the current. Therefore, as $S_{1}$ is switched on during this mode, $S_{1}$ has ZVT turn-on without conduction. Since $L_{r}$ resonates with $C_{r}$, the voltage on $L_{r}$ is identical to the minus voltage across $C_{r}$, thereby causing $i_{L r}$ to begin to drop. Moreover, the current $I_{L 1}$ is the sum of the currents of $i_{L r}, i_{S 1}$ and $i_{D r}$. As soon as $i_{L r}$ drops to $I_{L 1}$, this mode ends. During such a mode, the accompanying equations are described as below:

$$
\left\{\begin{array}{l}
i_{L r}(t)=i_{L r}\left(t_{2}\right) \cos \left(\omega_{1}\left(t-t_{2}\right)\right)-\frac{v_{C r}\left(t_{2}\right)}{Z_{1}} \sin \left(\omega_{1}\left(t-t_{2}\right)\right) \\
v_{C r}(t)=v_{C r}\left(t_{2}\right) \cos \left(\omega_{1}\left(t-t_{2}\right)\right)+i_{L r}\left(t_{2}\right) Z_{1} \sin \left(\omega_{1}\left(t-t_{2}\right)\right)
\end{array}\right.
$$

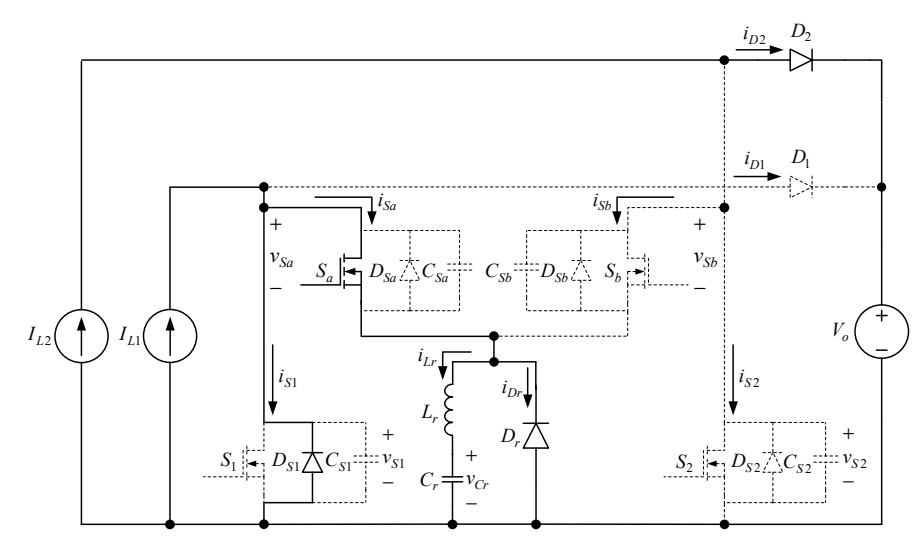

Figure 6. Current path in mode 3. 
Mode 4: $\left[\boldsymbol{t}_{3} \leq \boldsymbol{t} \leq \boldsymbol{t}_{4}\right]$. As in Figure 7, the current $i_{L r}$ is equal to the current $I_{L 1}$ at the instant $t_{3}$, and hence both the currents $i_{S 1}$ and $i_{D r}$ are zero, thereby causing the diodes $D_{S 1}$ and $D_{r}$ to be switched off. During this mode, the main switch $S_{1}$ is switched on with conduction. Meanwhile, the resonant inductor $L_{r}$ still resonates with the resonant capacitor $C_{r}$, and $i_{L r}$ is still reduced, but $i_{S 1}$ increases from zero gradually. Moreover, the current $I_{L 1}$ is the sum of the currents $i_{S 1}$ and $i_{S a}$, and $i_{S a}$ is identical to $i_{L r}$. As $i_{L r}$ drops to zero, the auxiliary switch $S_{a}$ is switched off, thereby causing $S_{a}$ to operate under ZCS turn-off. As soon as $i_{L r}$ is identical to zero, this mode ends.

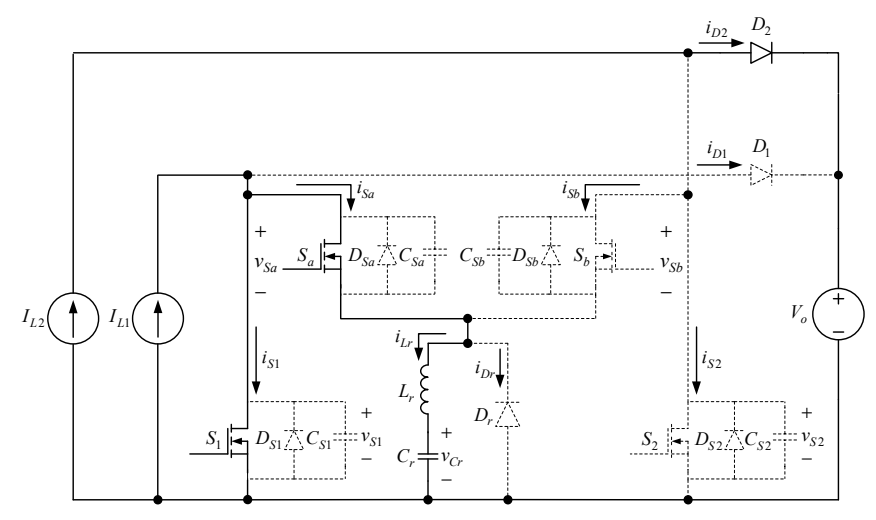

Figure 7. Current path in mode 4.

Mode 5: $\left[\boldsymbol{t}_{4} \leq \boldsymbol{t} \leq \boldsymbol{t}_{5}\right]$. As in Figure 8, the main switch $S_{1}$ remains switched on. During this mode, the resonant inductor $L_{r}$ still keeps resonating with the resonant capacitor $C_{r}$, and the current $i_{L r}$ increases in the negative direction and flows through $S_{1}$, thereby making the parasitic diode of the auxiliary switch $S_{a}$, called $D_{S a}$, switched on. Moreover, as soon as $i_{L r}$ goes from the minimum value to zero, this mode ends.

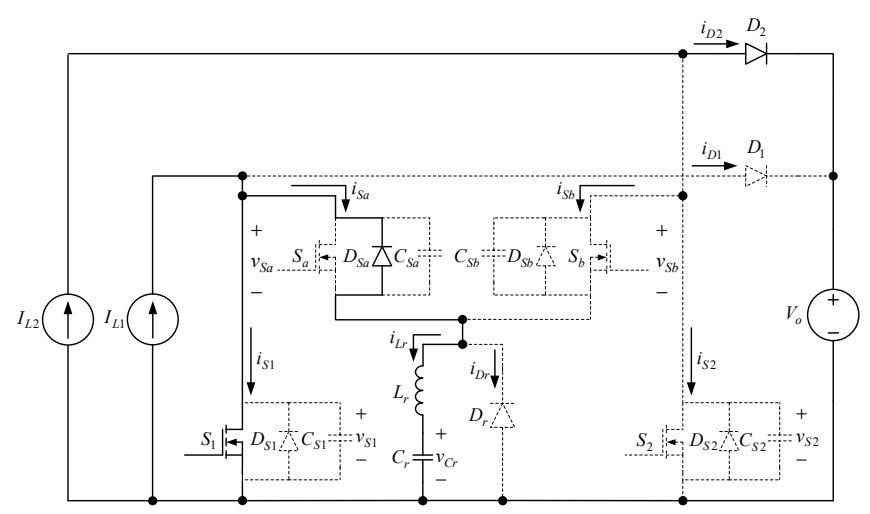

Figure 8. Current path in mode 5.

Mode 6: $\left[\boldsymbol{t}_{5} \leq \boldsymbol{t} \leq \boldsymbol{t}_{6}\right]$. As in Figure 9, the main switch $S_{1}$ still remains switched on. During this mode, the resonant inductor $L_{r}$, with its current in the positive direction, resonates with the resonant capacitor $C_{r}$, thereby making the resonant diode $D_{r}$ switched on and hence a resonant loop is generated. Moreover, the current in the main switch $S_{1}$, called $i_{S 1}$, is identical to the current $I_{L 1}$. As soon as $S_{1}$ is switched off, this mode ends.

Mode 7: $\left[t_{6} \leq t \leq t_{7}\right]$. As in Figure 10, the main switch $S_{1}$ is switched off at the instant $t_{6}$. During this mode, the current $I_{L 1}$ charges the parasitic capacitor of the main switch $S_{1}$, called $C_{S 1}$, and the parasitic capacitor of the auxiliary switch $S_{a}$, called $C_{S a}$, causing the voltage across $S_{1}$ to be increased. Moreover, the resonant loop is the same as that displayed in mode 6. As soon as the voltage $v_{S 1}$ is identical to the output voltage $V_{o}$, this mode ends. 


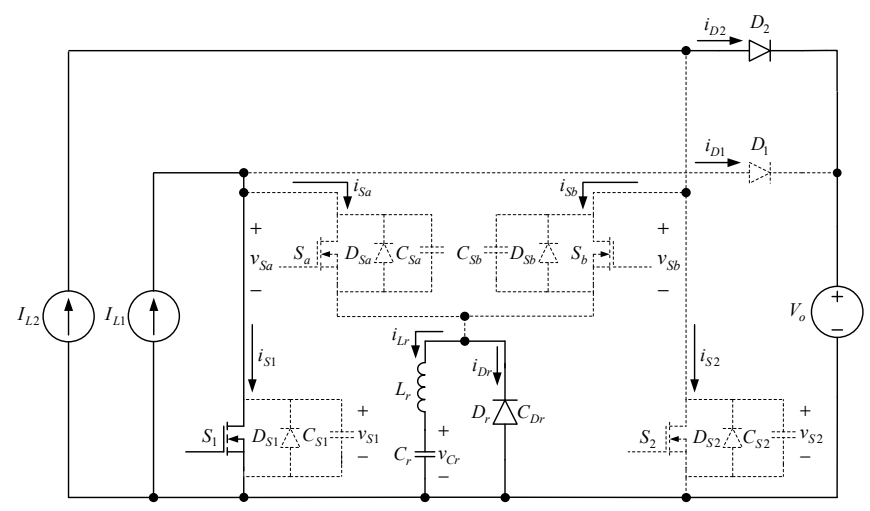

Figure 9. Current path in mode 6.

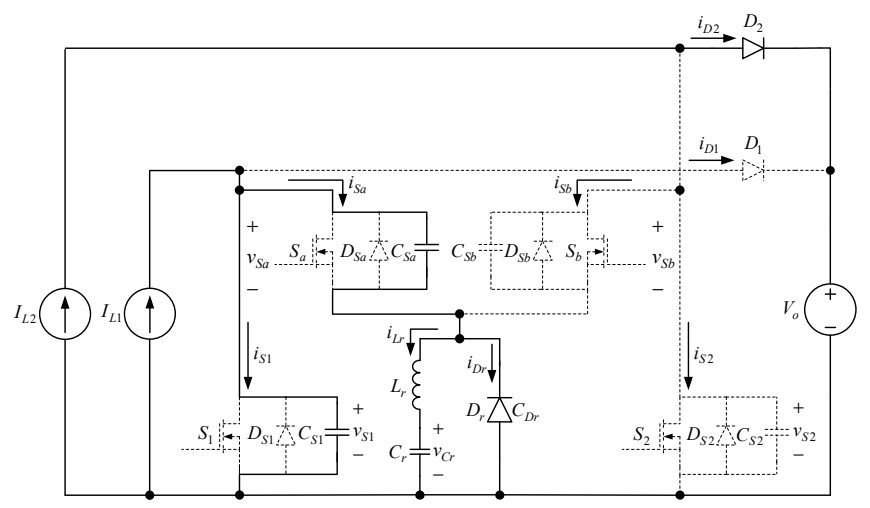

Figure 10. Current path in mode 7.

Mode 8: $\left[\boldsymbol{t}_{7} \leq \boldsymbol{t} \leq \boldsymbol{t}_{8}\right]$. As in Figure 11, during this mode, all the switches are switched off, but only the output diode $D_{1}$ conducts with the current $i_{D 1}$ identical to the current $I_{L 1}$. Moreover, the resonant loop is the same as that displayed in mode 7 . As soon as the main switch $S_{b}$ is switched on, this mode ends, and hence the other phase begins to work, coming back to state 1 until this cycle is finished. After this, the next period will be repeated.

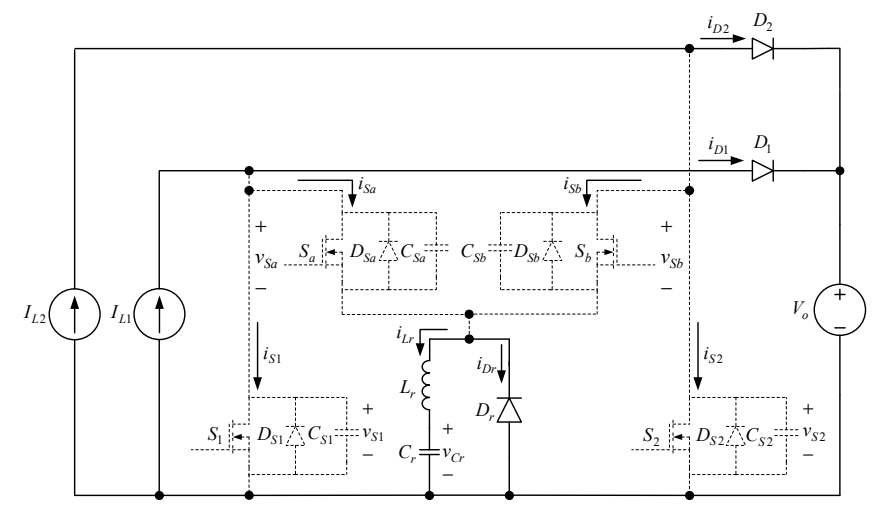

Figure 11. Current path in mode 8.

\section{Current Control Strategy}

Figure 12 displays the proposed current-balancing control strategy. The duty cycle of the gate-driving signal $v_{g 1}$ for the first phase after the first pulse-width modulation (PWM) generator is tuned to get the wanted output voltage $V_{o}$, based on the voltage loop with the controller $G_{c 1}(z)$ having the voltage command reference $V_{\text {ref }}$ and the digital sensed voltage $V_{0}^{\prime}$, which is obtained from the 
sensed voltage $v_{0}^{\prime}$ by the voltage divider with a gain $k$ and the first analog-to-digital converter (ADC1). Meanwhile, the sensed current of the first phase, named $i_{L 1}^{\prime}$, is sent to ADC2, to get the digital sensed current $I_{L 1}^{\prime}$, which will be used as the current command reference for the current-balancing loop with the controller $G_{c 2}(z)$ having the digital sensed current $I_{L 2}^{\prime}$ from the sensed current of the second phase, named $i_{L 2}^{\prime}$, after ADC3, so that the duty cycle of the gate-driving signal $v_{g_{2}}$ for the second phase after the second PWM generator is automatically tuned to force the input current to be evenly distributed between the two phases and hence the load current balancing between the two phases can be realized.

Afterwards, the current-balancing behavior is described below. First, by assuming that the output power $\left(P_{o}\right)$ is identical to the input power $\left(P_{i}\right)$, the output current $\left(I_{o}\right)$ is identical to the product of the DC inductor current $\left(I_{L}\right)$ and one minus duty cycle (1-D). Therefore, if $I_{L}=I_{L 1}+I_{L 2}$ and $I_{O}=I_{O 1}+$ $I_{o 2}$, then under $I_{L 1}=I_{L 2}=0.5 I_{L}, I_{o}=0.5 I_{L 1}\left(1-D_{a}\right)+0.5 I_{L 2}\left(1-D_{b}\right)$, where $D_{a}$ is the duty cycle of $v_{g 1}$ generated from the controller $G_{c 1}(z)$ and $D_{b}$ is the duty cycle of $v_{g 2}$ generated from the controller $G_{c 2}$ $(z)$. For example, if $I_{o 1}$ is larger than $I_{o 2}$, then $D_{a}$ will be increased and $D_{b}$ will be decreased, thereby causing $I_{01}$ to go down and $I_{02}$ to go up. Eventually, both $I_{01}$ and $I_{02}$ are equal to $0.5 I_{0}$, making the current balancing realized.

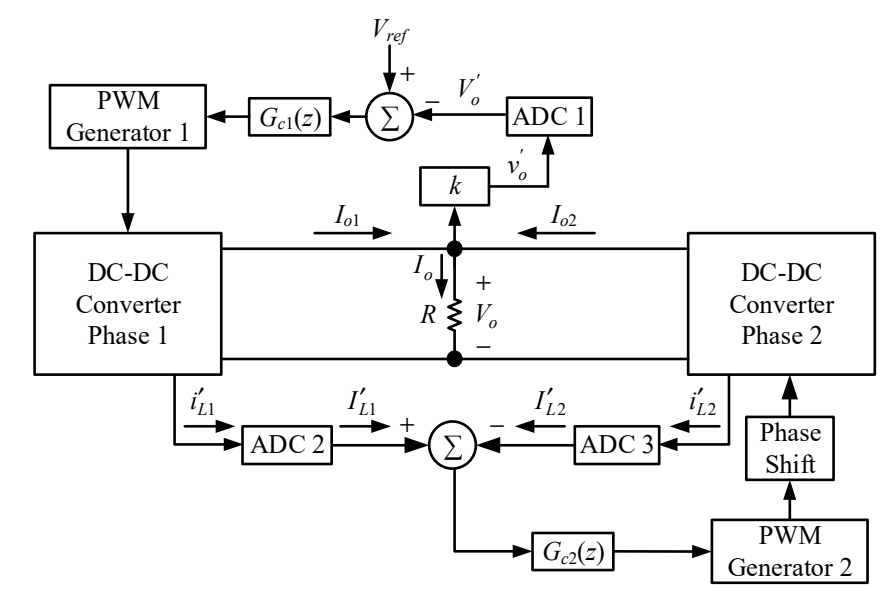

Figure 12. Proposed current-balancing control strategy (ADC: analog-to-digital converter; PWM: pulse-width modulation).

\section{Design Considerations}

Prior to designing the key parameters of this converter, the associated specifications of the system are shown in Table 1.

Table 1. System Specifications (CCM: continuous current mode)

\begin{tabular}{cc}
\hline System Parameters & Specifications \\
\hline Operating Mode & $\mathrm{CCM}$ \\
Input Voltage & $24 \mathrm{~V}$ \\
Switching Frequency & $50 \mathrm{kHz}$ \\
Output Voltage & $36 \mathrm{~V}$ \\
Rated Output Power/Current & $216 \mathrm{~W} / 6 \mathrm{~A}$ \\
Min. Output Power/Current & $21.6 \mathrm{~W} / 0.6 \mathrm{~A}$ \\
\hline
\end{tabular}

\subsection{Design of $L_{1}$ and $L_{2}$}

Since this converter is a two-phase structure, the values of the input inductors can be approximately decided by a single phase with the rated output power/current reduced by a factor of 2 . Moreover, the converter operates in the CCM, so the minimum value of $L_{1}$, called $L_{1, \min }$, can be represented by 


$$
L_{1} \geq \frac{R D_{a}\left(1-D_{a}\right)^{2} T_{s}}{2}
$$

where $R$ is the output resistor, whose value is located between $12 \Omega$ and $120 \Omega$.

Based on (9), the maximum duty cycle is obtained to be 0.33 , which corresponds to the input voltage of $24 \mathrm{~V}$ and the output voltage of $36 \mathrm{~V}$. Therefore, $L_{1, \min }=178 \mu \mathrm{H}$ after some calculations, and eventually the value of $L_{1}$ is chosen to be $200 \mu \mathrm{H}$, which is also for the value of $L_{2}$.

\subsection{Design of $C_{o}$}

Regarding the output capacitor design, Equation (11) is used on condition that the maximum output voltage ripple is equal to $20 \%$ of the output voltage $V_{o}$, the value of $R$ is $12 \Omega, T_{S}$ is $20 \mu \mathrm{s}$, $D=0.33$, and $V_{o}=36 \mathrm{~V}$. After some calculations, the value of $C_{o}$ is larger than $275 \mu \mathrm{F}$. Eventually, a $470 \mu \mathrm{F}$ capacitor is chosen, and this is because the value of the electrolytic capacitor will be decreased if the frequency is increased:

$$
\Delta v_{0}=\Delta v_{C_{0}}=\frac{1}{C_{o}} \int{ }_{0}^{D T_{s}} i_{C_{0}} d t=\frac{I_{o} D T_{s}}{C_{o}}=\frac{V_{o} D T_{s}}{R C_{o}}
$$

\subsection{Design of $L_{r}$ and $C_{r}$}

The proposed soft switching structure is based on the turn-on of the auxiliary switch $S_{a /}$ prior to the turn-on of the main switch $S_{1}$, so that the resonant inductor $L_{r}$ resonates with the resonant capacitor $C_{r}$ and the parasitic capacitor of $S_{1}$, called $C_{S 1}$. As the current $i_{L r}$ is larger than the current $I_{L 1}$, the voltage across $S_{1}$, called $v_{S 1}$, drops to zero abruptly, the parasitic diode of $S_{1}$, called $D_{S 1}$, is switched on, and afterwards $S_{1}$ is switched on with ZVT. To avoid the converter operating abnormally, the time interval, used to execute resonance, is not too long. Therefore, the turn-on time interval of the auxiliary switch $S_{a}$ is chosen to be one tenth of the switching period $T_{s}$, about $2 \mu$ s. Meanwhile, to reduce the effect of $i_{L r}$ on $S_{1}$, the turn-on instant of $S_{a}$ is prior to the turn-on instant of $S_{1}$ by one fifth of the turn-on time interval of $S_{a}$, namely $0.4 \mu \mathrm{s}$. Hence, to obtain the soft switching of $S_{1}$, the time interval for $v_{S 1}$ to drop to zero is chosen to be $0.5 \mu$ s or less as shown in (11):

$$
\left(t_{1}-t_{0}\right)+\left(t_{2}-t_{1}\right) \leq 0.5 \mu \mathrm{s}
$$

where during the time interval between $t_{1}$ and $t_{0}$, the resonant current $i_{L r}$ rises from zero to the current $I_{L 1}$, whereas during the time interval between $t_{2}$ and $t_{1}$, the voltage across $S_{1}$ drops from the output voltage $V_{o}$ to zero.

In Equation (11), the former time interval was quite significantly larger than the latter time interval, so the former time interval at a rated load is set at half of the time interval between the turn-on instant of $S_{a}$ and the turn-on instant of $S_{1}$, namely $0.2 \mu \mathrm{s}$, so as to make sure that $S_{1}$ can operate under ZVT turn-on within the time interval of $0.5 \mu \mathrm{s}$. Therefore, the following equation can be obtained to be:

$$
\left(t_{1}-t_{0}\right)=\frac{1}{\omega_{1}} \sin ^{-1}\left[\frac{I_{L 1} Z_{1}}{V_{o}}\right]=0.2 \mu \mathrm{s}
$$

To make sure that the resonant period of the auxiliary circuit, called $T_{1}$, can make the ZVS turn-on of the main switches $S_{1}$ and $S_{2}$ happen within the switching period $T_{s}, T_{1}$ is set at $0.75 T_{s}$, equal to $7.5 \mu \mathrm{s}$, and afterwards, based on (12), the values of $L_{r}$ and $C_{r}$ can be determined to be $1.25 \mu \mathrm{H}$ and $1.14 \mu \mathrm{F}$.

\section{Experimental Results}

To verify the performance of the proposed soft switching control strategy, the waveforms of the converter operating at minimum and rated loads are given. Figures $13-23$ are for the converter 
operating at a minimum load, whereas Figures 24-34 are for the converter operating at a rated load. Figure 13 displays $v_{g 1}$ and $v_{g 2}$ for $S_{1}$ and $S_{2}$, respectively. Figure 14 displays $v_{g 1}$ and $v_{g a}$ for $S_{1}$ and $S_{a}$, respectively, whereas Figure 15 shows $v_{g 2}$ and $v_{g b}$ for $S_{2}$ and $S_{b}$, respectively. Figure 16 displays $i_{L r}$ and $v_{C r}$. Figure 17 shows $v_{S 1}, i_{L 1}$ and $i_{L r}$. Figure 18 displays $v_{S 2}, i_{L 2}$ and $i_{L r}$. Figure 19 shows $v_{g 1}$, $v_{S 1}$ and $i_{S 1}$. Figure 20 displays $v_{g 2}, v_{S 2}$ and $i_{S 2}$. Figure 21 displays $v_{g a}, v_{S a}$ and $i_{S a}$. Figure 22 displays $v_{g b}, v_{S b}$ and $i_{S b}$. Figure 23 shows the current balancing between the two phases. As for Figures 24-34, the measured items are the same as those for Figures 13-23.

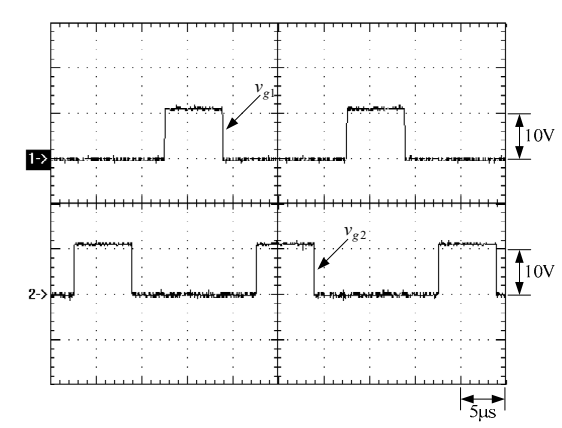

Figure 13. Waveforms pertaining to $S_{1}$ and $S_{a}$ at the minimum load: (1) $v_{g 1}$; and (2) $v_{g_{2}}$.

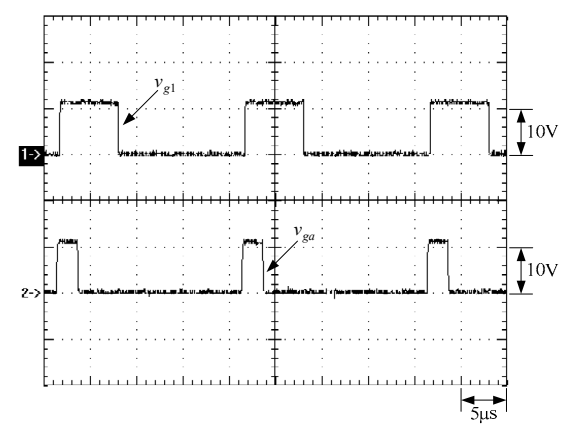

Figure 14. Waveforms pertaining to $S_{1}$ and $S_{a}$ at the minimum load: (1) $v_{g 1}$; and (2) $v_{g a}$.

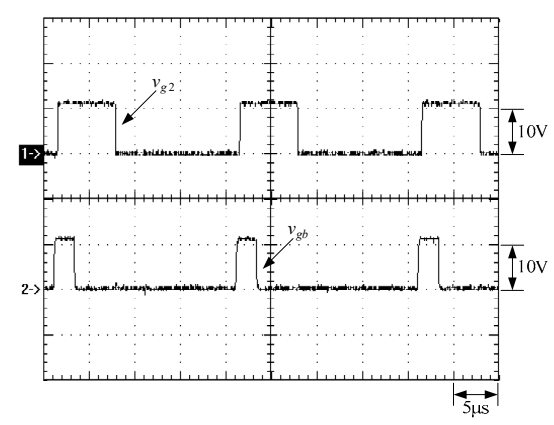

Figure 15. Waveforms pertaining to $S_{2}$ and $S_{b}$ evenly at the minimum load: (1) $v_{g 2}$; and (2) $v_{g b}$.

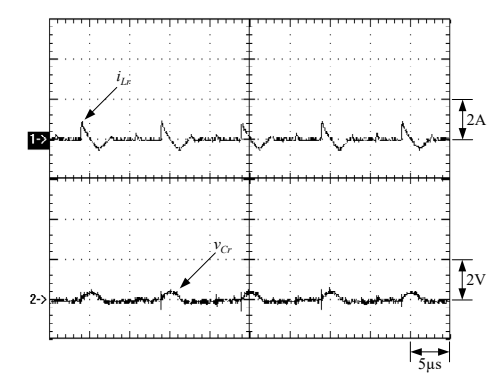

Figure 16. Waveforms pertaining to $L_{r}$ and $C_{r}$ at the minimum load: (1) $i_{L r}$; and (2) $v_{C r}$. 


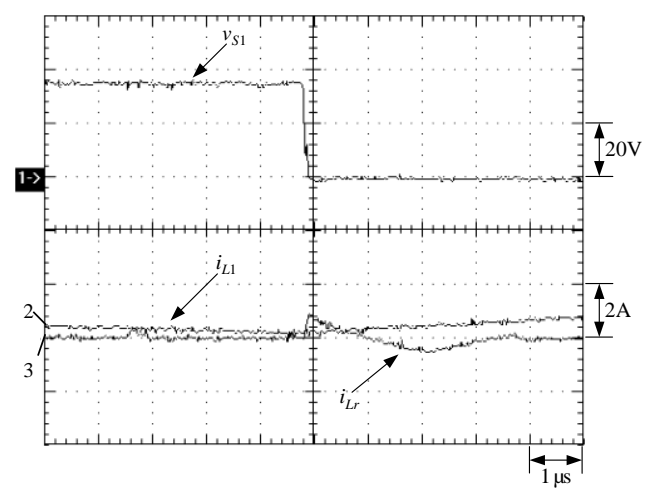

Figure 17. Waveforms pertaining to $S_{1}, L_{1}$ and $L_{r}$ at the minimum load: (1) $v_{S 1} ;(2) i_{L 1}$; and (3) $i_{L r}$.

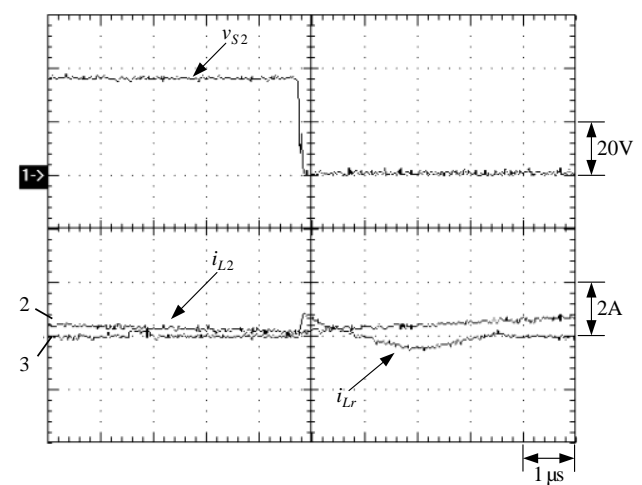

Figure 18. Waveforms pertaining to $S_{2}, L_{2}$ and $L_{r}$ at the minimum load: (1) $v_{S 2} ;(2) i_{L 2}$; and (3) $i_{L r}$.

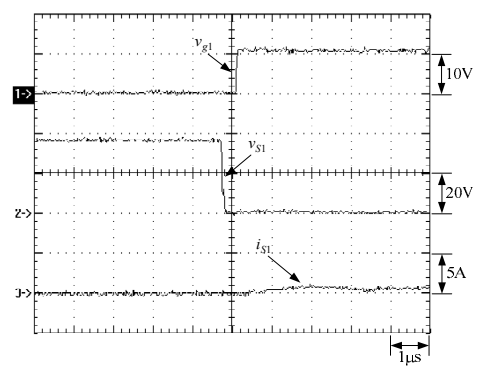

Figure 19. Waveforms pertaining to $S_{1}$ at the minimum load: (1) $v_{g 1}$; (2) $v_{S 1}$; and (3) $i_{S 1}$.

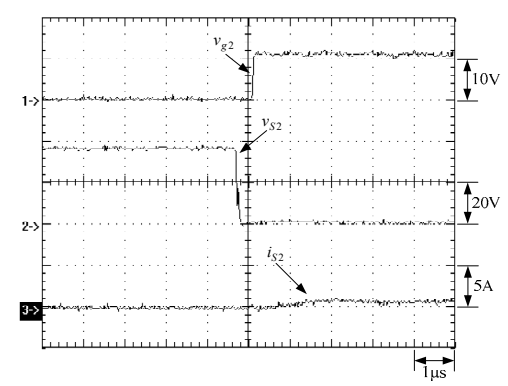

Figure 20. Waveforms pertaining to $S_{2}$ at the minimum load: (1) $v_{g 2} ;(2) v_{S 2}$; and (3) $i_{S 2}$.

From Figures 13-24, we can see that $v_{g 2}$ is shifted from $v_{g 1}$ by 180 degrees. From Figures 14 and $25, S_{a}$ is switched on before $S_{1}$ is switched on, whereas from Figures 15 and 26, we can see that $S_{b}$ is switched on before $S_{2}$ is switched on. In Figures 16 and 27, we can see that $L_{r}$ resonates with $C_{r}$. From Figures 17 and 28, we can see that as $S_{a}$ is switched on prior to $S_{1}, i_{L r}$ is rising abruptly and then is larger than $i_{L 1}$, causing the voltage across $C_{S 1}$ to be dropped to zero and then $S_{1}$ to be switched on with ZVT, whereas from Figures 18 and 29, we can see that as $S_{b}$ is switched on prior to $S_{2}, i_{L r}$ is rising 
abruptly and then is larger than $i_{L 2}$, causing the voltage across $C_{S 2}$ to be dropped to zero and then $S_{2}$ to be switched on with ZVT. From Figures 19 and 30, we can see that $S_{1}$ has ZVT turn-on, whereas from Figures 20 and 31, we can see that $S_{2}$ has ZVT turn-on. From Figures 21 and 32, we can see that due to resonance, $i_{S a}$ is dropped to zero and then clamped at zero, thereby making $S_{a}$ switched off with ZCS, whereas from Figures 22 and 33, we can see that due to resonance, $i_{S b}$ is dropped to zero and then clamped at zero, thereby making $S_{b}$ switched off with ZCS. From Figures 23 and 34 , we can see that the current balancing between the two phases performs well for any load.

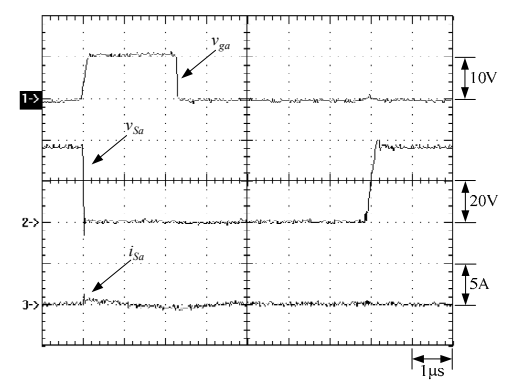

Figure 21. Waveforms pertaining to $S_{a}$ at the minimum load: (1) $v_{g a} ;(2) v_{S a}$; and (3) $i_{S a}$.

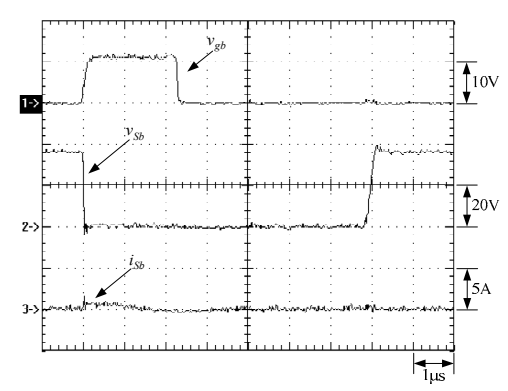

Figure 22. Waveforms pertaining to $S_{b}$ at the minimum load: (1) $v_{g b} ;(2) v_{S b}$; and (3) $i_{S b}$.

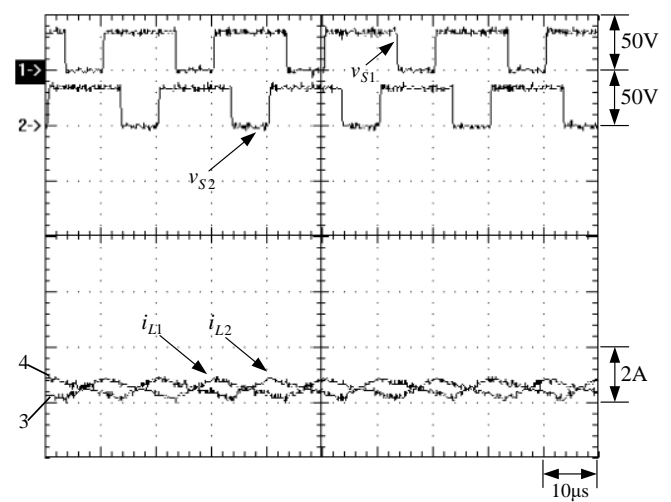

Figure 23. Waveforms pertaining to current balancing at the minimum load: $(1) v_{S 1}$; (2) $v_{S 2} ;(3) i_{L 1}$; and (4) $i_{L 2}$.

From Figures 13-35, we can know that all over the load range, both the main switches have ZVT turn-on and both the auxiliary switches have ZCS turn-off. 


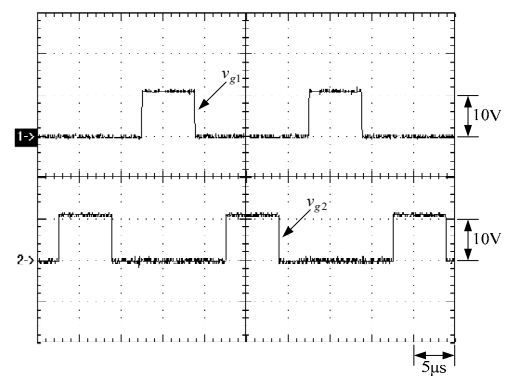

Figure 24. Waveforms pertaining to $S_{1}$ and $S_{a}$ at the rated load: (1) $v_{g 1}$; and (2) $v_{g 2}$.

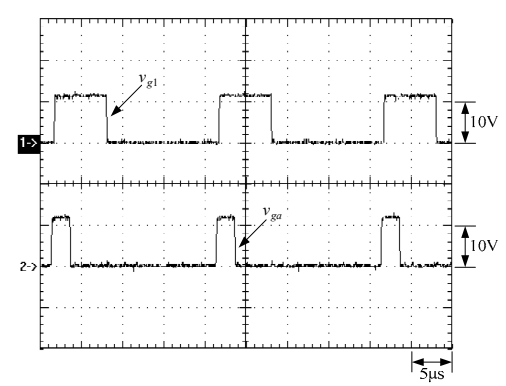

Figure 25. Waveforms pertaining to $S_{1}$ and $S_{a}$ at the rated load: (1) $v_{g 1}$; and (2) $v_{g a}$.

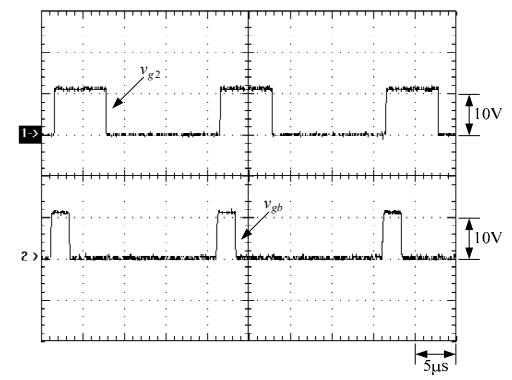

Figure 26. Waveforms pertaining to $S_{2}$ and $S_{b}$ at the rated load: (1) $v_{g 2}$; and (2) $v_{g b}$.

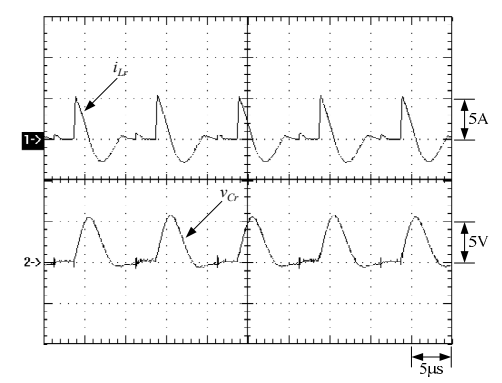

Figure 27. Waveforms pertaining to $L_{r}$ and $C_{r}$ at the rated load: (1) $i_{L r}$; and (2) $v_{C r}$. 


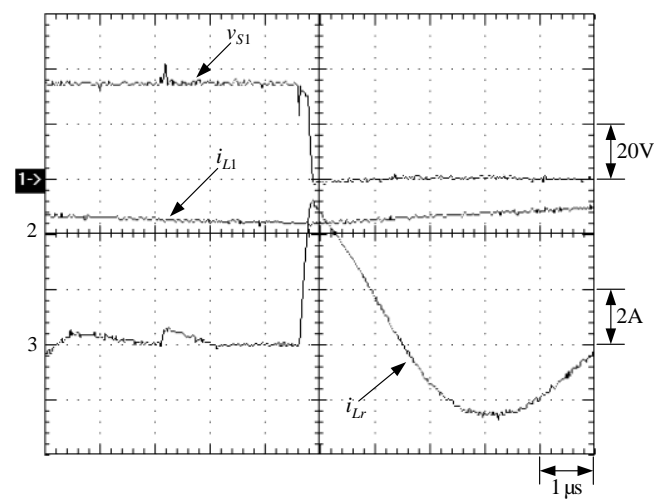

Figure 28. Waveforms pertaining to $S_{1}, L_{1}$ and $L_{r}$ at the rated load: (1) $v_{S 1}$; (2) $i_{L 1}$; and (3) $i_{L r}$.

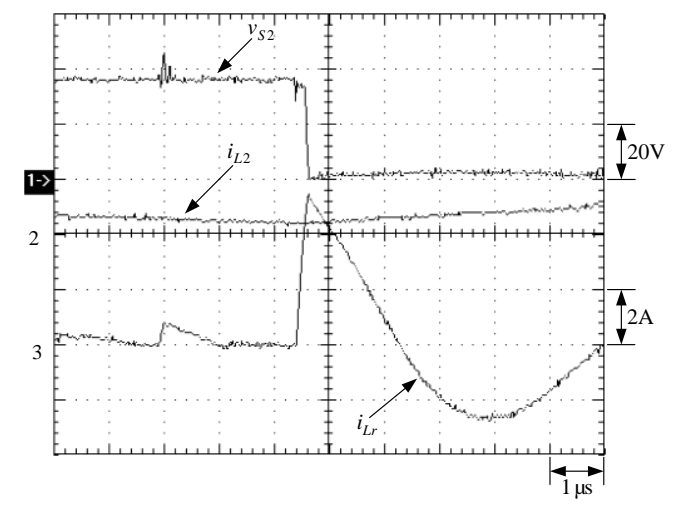

Figure 29. Waveforms pertaining to $S_{2}, L_{2}$ and $L_{r}$ at the rated load: (1) $v_{S 2} ;(2) i_{L 2}$; and (3) $i_{L r}$.

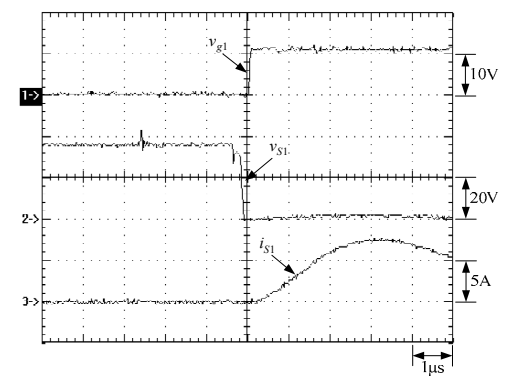

Figure 30. Waveforms pertaining to $S_{1}$ at the rated load: (1) $v_{g 1} ;(2) v_{S 1}$; and (3) $i_{S 1}$.

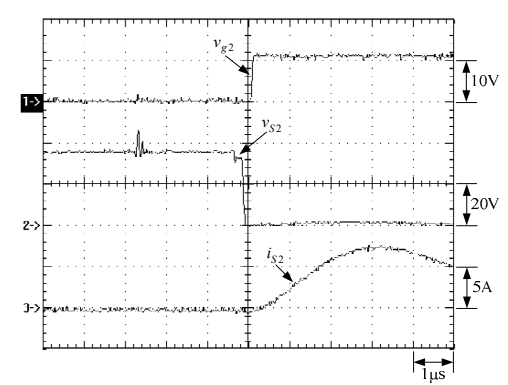

Figure 31. Waveforms pertaining to $S_{2}$ at the rated load: (1) $v_{g 2} ;(2) v_{S 2}$; the (3) $i_{S 2}$. 


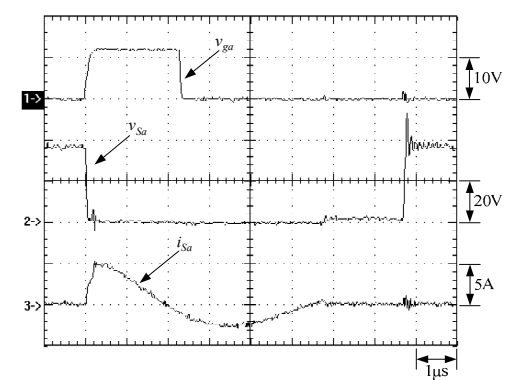

Figure 32. Waveforms pertaining to $S_{a}$ at the rated load: (1) $v_{g a} ;(2) v_{S a}$; and (3) $i_{S a}$.

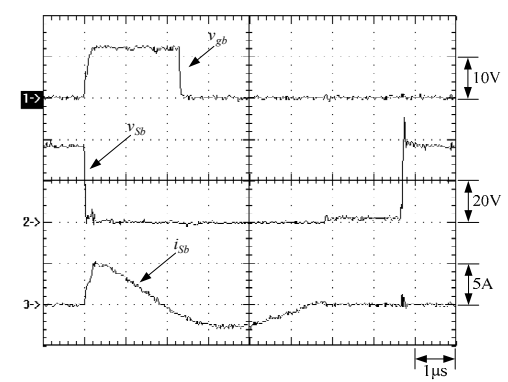

Figure 33. Waveforms pertaining to $S_{b}$ at the rated load: (1) $v_{g b} ;(2) v_{S b}$; and (3) $i_{S b}$.

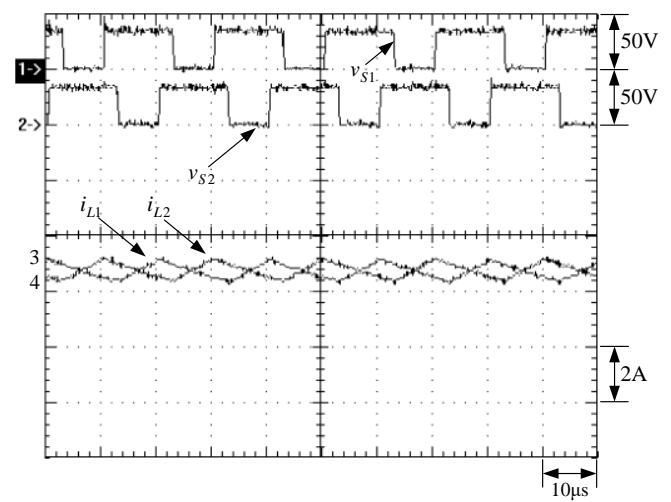

Figure 34. Waveforms pertaining to current balancing at the rated load: (1) $v_{S 1}$; (2) $v_{S 2} ;(3) i_{L 1}$; and (4) $i_{L 2}$.

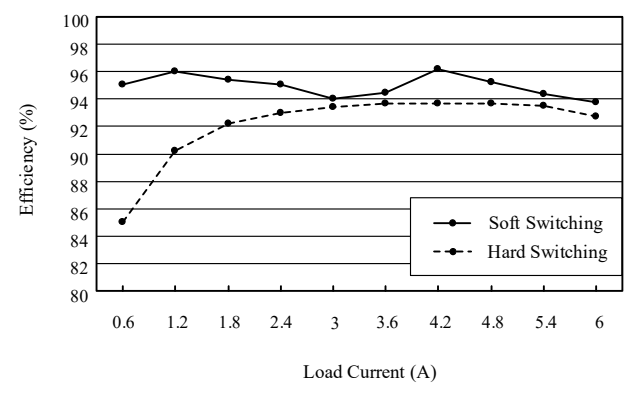

Figure 35. Efficiency vs. load current.

\section{Comparisons}

In Table 2, the numbers of resonant components are five, seven and five for the circuits from [37] and [47], and the proposed circuits, respectively. The circuit shown in [37] has ZCT turn-on and ZVT turn-off. The circuit displayed in [47] has ZVT turn-on and ZCT turn-off. The proposed circuit has ZVT turn-on. The minimum values of the overall efficiency are $84 \%, 91 \%$ and $94 \%$ for the circuits [37] 
and [47], and the proposed, respectively. The circuit [47] has ZVT turn-on and ZCT turn-off but the number of resonant components is seven, whereas the proposed circuit only has ZVT turn-on, but the number of resonant components is five. In general, the ZVS turn-on or ZVT turn-on is quite important for reducing the switching loss of the metal-oxide-semiconductor field-effect transistor (MOSFET) [48]. Accordingly, the proposed circuit has the best performance among the three.

Table 2. Comparisons between the circuits from [37], [47] and the proposed circuits (ZVS: zero-voltage switching; ZVT: zero-voltage transition; ZCS: zero-current switching; ZCT: zero-current transition).

\begin{tabular}{|c|c|c|c|c|c|c|c|c|c|c|c|}
\hline \multirow{3}{*}{ Comparisons } & \multirow{3}{*}{$\begin{array}{c}\text { Resonant } \\
\text { Count } \\
\text { No. }\end{array}$} & \multicolumn{8}{|c|}{ Soft Switching Type for Main Switches } & \multirow{2}{*}{\multicolumn{2}{|c|}{$\begin{array}{c}\text { Overall } \\
\text { Efficiency }\end{array}$}} \\
\hline & & & Tur & - On & & & Turı & -Off & & & \\
\hline & & ZVS & ZVT & ZCS & $\mathrm{ZCT}$ & ZVS & ZVT & ZCS & ZCT & Min. & Max. \\
\hline [37] & 5 & & & & * & & * & & & $84 \%$ & $90 \%$ \\
\hline [47] & 7 & & * & & & & & & * & $91 \%$ & $93 \%$ \\
\hline Proposed & 5 & & * & & & & & & & $94 \%$ & $96 \%$ \\
\hline
\end{tabular}

\section{Conclusions}

In this paper, to reduce the switching loss as well as to upgrade the overall efficiency, the proposed converter with the main switches $S_{1}$ and $S_{2}$ had ZVT turn-on as well as the auxiliary switches $S_{a}$ and $S_{b}$ having ZCS turn-off. All the soft switching operations are achieved based on only one resonant loop. The ZVT behavior is realized by switching on the auxiliary switch $S_{a}$ (or $S_{b}$ ) before the main switch $S_{1}$ (or $S_{2}$ ) is switched on, so that the voltage across $S_{1}$ (or $S_{2}$ ) is dropped to zero and hence $S_{1}\left(\right.$ or $S_{2}$ ) has an ZVT turn-on. On the other hand, the ZCS behavior was achieved based on the characteristics of the auxiliary circuit, so that $S_{a}$ and $S_{b}$ have a ZCS turn-off. From the experimental results, we can know that soft switching can be realized all over the load range. In addition, the current balancing between the two phases is performed well for any load.

Author Contributions: Conceptualization, Y.-T.Y.; methodology, K.-I.H.; software, W.-Z.J.; validation, W.-Z.J.; formal analysis, W.-Z.J.; investigation, Y.-T.Y.; resources, K.-I.H.; data curation, Y.-T.Y.; writing—original draft preparation, K.-I.H.; writing-review and editing, K.-I.H.; visualization, Y.-T.Y.; supervision, K.-I.H.; project administration, K.-I.H.; funding acquisition, K.-I.H. All authors have read and agreed to the published version of the manuscript.

Funding: This research was funded by the Ministry of Science and Technology, Taiwan, under the Grant Number: MOST 108-2221-E-027-051.

Acknowledgments: The authors gratefully acknowledge the support of the Ministry of Science and Technology, Taiwan, under the Grant Number MOST 108-2221-E-027-051.

Conflicts of Interest: The authors declare no conflict of interest with commerce.

\section{References}

1. Lee, F.C. High-frequency quasi-resonant converter technologies. Proc. IEEE 1988, 76, 377-390. [CrossRef]

2. Lee, F.C. High-frequency quasi-resonant and multi-resonant converter technologies. In Proceedings of the IEEE IECON'88, Singapore, 24-28 October 1988; IEEE: New York, NY, USA; Volume 3, pp. 509-521.

3. Vorperian, V. Quasi-square-wave converters: Topologies and analysis. IEEE Trans. Power Electron. 1988, 3, 183-191. [CrossRef]

4. Hua, G.; Lee, F.C. Soft-switching techniques in PWM converters. IEEE Trans. Ind. Electron. 1995, 42, 595-603. [CrossRef]

5. Chuang, Y.C.; Ke, Y.L. A novel high-efficiency battery charger with a buck zero-voltage-switching resonant converter. IEEE Trans. Energy Convers. 2007, 22, 848-854. [CrossRef]

6. Hui, S.Y.R.; Cheng, K.W.E.; Prakash, S.R.N. A fully soft-switched extended-period quasi-resonant power-factor-correction circuit. IEEE Trans. Power Electron. 1997, 12, 922-930. [CrossRef]

7. Watson, R.; Lee, F.C.; Hua, G.C. Utilization of an active-clamp circuit to achieve soft switching in flyback converters. IEEE Trans. Power Electron. 1996, 11, 162-169. [CrossRef] 
8. Watson, R.; Hua, G.C.; Lee, F.C. Characterization of an active clamp flyback topology for power factor correction applications. IEEE Trans. Power Electron. 1996, 11, 191-198. [CrossRef]

9. Lee, Y.S.; Lin, B.T. Adding active clamping and soft switching to boost-flyback single-stage isolated power-factor-corrected power supplies. IEEE Trans. Power Electron. 1997, 12, 1017-1027.

10. Duarte, C.M.C.; Barbi, I. A family of ZVS-PWM active-clamping DC-to-DC converters: Synthesis, analysis, design, and experimentation. IEEE Trans. Circuits Syst. I Fundam. Theory Appl. 1997, 44, 698-704. [CrossRef]

11. Zhao, Q.; Lee, F.C. High-efficiency, high step-up DC-DC converters. IEEE Trans. Power Electron. 2003, 18, 65-73. [CrossRef]

12. Han, S.K.; Yoon, H.K.; Moon, G.W.; Youn, M.J.; Kim, Y.H.; Lee, K.H. A new active clamping zero-voltage switching PWM current-fed half-bridge converter. IEEE Trans. Power Electron. 2005, 20, 1271-1279. [CrossRef]

13. Tuomainen, V.; Kyyra, J. Effect of resonant transition on efficiency of forward converter with active clamp and self-driven SRs. IEEE Trans. Power Electron. 2005, 20, 315-323. [CrossRef]

14. Lo, Y.K.; Lin, J.Y. Active-clamping ZVS flyback converter employing two transformers. IEEE Trans. Power Electron. 2007, 22, 2416-2423. [CrossRef]

15. Lin, B.R.; Hsieh, F.Y. Soft-switching zeta-flyback converter with a buck-boost type of active clamp. IEEE Trans. Ind. Electron. 2007, 54, 2813-2822.

16. Chen, M.; Sun, J. Reduced-order averaged modeling of active-clamp converters. IEEE Trans. Power Electron. 2006, 21, 487-494. [CrossRef]

17. Suryawanshi, H.M.; Ramteke, M.R.; Thakre, K.L.; Borghatem, V.B. Unity- power-factor operation of three-phase AC-DC soft switched converter based on boost active clamp topology in modular approach. IEEE Trans. Power Electron. 2008, 23, 229-236. [CrossRef]

18. Wu, T.F.; Lai, Y.S.; Hung, J.C.; Chen, Y.M. Boost converter with coupled inductors and buck-boost type of active clamp. IEEE Trans. Ind. Electron. 2008, 55, 154-162. [CrossRef]

19. Wu, X.; Zhang, J.; Ye, X.; Qian, Z. Analysis and derivations for a family ZVS converter based on a new active clamp ZVS cell. IEEE Trans. Ind. Electron. 2008, 55, 773-781. [CrossRef]

20. Wu, X.; Zhang, J.; Ye, X.; Qian, Z. Analysis and design for a New ZVS DC-DC converter with active clamping. IEEE Trans. Power Electron. 2006, 21, 1572-1579. [CrossRef]

21. Hua, G.; Leu, C.S.; Jiang, Y.; Lee, F.C.Y. Novel zero-voltage- transition PWM converters. IEEE Trans. Power Electron. 1994, 9, 213-219.

22. Tseng, C.J.; Chen, C.L. Novel ZVT-PWM converters with active snubbers. IEEE Trans. Power Electron. 1998, 13, 861-869. [CrossRef]

23. Cho, J.G.; Baek, J.W.; Yoo, D.W.; Lee, H.S. Reduced conduction loss zero-voltage-transition power factor correction converter with low cost. IEEE Trans. Ind. Electron. 1998, 45, 395-400.

24. Tseng, C.J.; Chen, C.L. A novel ZVT PWM Cuk power-factor corrector. IEEE Trans. Ind. Electron. 1999, 46, 780-787. [CrossRef]

25. Gurunathan, R.; Bhat, A.K.S. ZVT boost converter using a ZCS auxiliary circuit. IEEE Trans. Aerosp. Electron. Syst. 2001, 37, 889-897. [CrossRef]

26. Gurunathan, R.; Bhat, A.K.S. A zero-voltage transition boost converter using a zero-voltage switching auxiliary circuit. IEEE Trans. Power Electron. 2002, 17, 658-668. [CrossRef]

27. Bodur, H.; Bakan, A.F. A new ZVT-ZCT-PWM DC-DC converter. IEEE Trans. Power Electron. 2004, 19, 676-684. [CrossRef]

28. Jain, N.; Jain, P.K.; Joos, G.A. Zero voltage transition boost converter employing a soft switching auxiliary circuit with reduced conduction losses. IEEE Trans. Power Electron. 2004, 19, 130-139. [CrossRef]

29. Martins, M.L.D.S.; Hey, H.L. Self-commutated auxiliary circuit ZVT PWM converters. IEEE Trans. Power Electron. 2004, 19, 1435-1445. [CrossRef]

30. Schuch, L.; Rech, C.; Hey, H.L.; Pinheiro, J.R. Integrated ZVT auxiliary commutation circuit for input stage of double-conversion UPSs. IEEE Trans. Power Electron. 2004, 19, 1486-1497. [CrossRef]

31. Yang, S.P.; Lin, J.L.; Chen, S.J. A novel ZCZVT forward converter with synchronous rectification. IEEE Trans. Power Electron. 2006, 21, 912-922. [CrossRef]

32. Chuang, Y.C.; Ke, Y.L. High-efficiency and low-stress ZVT-PWM DC-to-DC converter for battery charger. IEEE Trans. Ind. Electron. 2008, 55, 3030-3037. [CrossRef]

33. Huang, W.; Gao, X.; Bassan, S.; Moschopoulos, G. Novel dual auxiliary circuits for ZVT-PWM converters. Can. J. Electr. Comput. Eng. 2008, 33, 153-160. [CrossRef] 
34. Carlos Marcelo de Oliveira Stein; Hey, H.L. A true ZCZVT commutation cell for PWM converters. IEEE Trans. Power Electron. 2000, 15, 185-193. [CrossRef]

35. Hu, Z.; Zhang, B.; Deng, W.H. Study on novel ZVZCT PWM DC-DC converter family. In Proceedings of the IEEE IPEMC'04, Xi'an, China, 14-16 August 2004; IEEE: New York, NY, USA, 2004; Volume 1, pp. 154-159.

36. Cho, J.G.; Baek, J.W.; Rim, G.H.; Kang, I. Novel zero-voltage-transition PWM multiphase converters. IEEE Trans. Power Electron. 1998, 13, 152-159.

37. Tseng, S.Y.; Shiang, J.Z.; Chang, H.H.; Jwo, W.S.; Hsieh, C.T. A novel turn-on/off snubber for interleaved boost converters. In Proceedings of the IEEE PESC'07, Orlando, FL, USA, 17-21 June 2007; IEEE: New York, NY, USA, 2007; pp. 2341-2347.

38. Hwu, K.I.; Tu, W.C.; Hon, M.J. A dimmable LED driver based on current balancing transformer with magnetizing energy recycling considered. IEEE J. Disp. Technol. 2014, 10, 388-395. [CrossRef]

39. Hwu, K.I.; Jiang, W.Z.; Hsiao, C.W. Dimmable LED driver based on twin-bus converter and differential-mode transformer. IEEE J. Disp. Technol. 2016, 12, 1122-1129. [CrossRef]

40. Qu, X.; Wong, S.C.; Tse, C.K. An improved LCLC current-source-output multistring LED driver with capacitive current balancing. IEEE Trans. Power Electron. 2015, 30, 5783-5791. [CrossRef]

41. Hwu, K.I.; Tai, Y.K.; Tu, H.H. Implementation of a dimmable LED driver with extendable parallel structure and capacitive current sharing. Appl. Sci. 2019, 9, 5177. [CrossRef]

42. Chiub, C.L.; Chen, K.H. A high accuracy current-balanced control technique for LED backlight. In Proceedings of the IEEE PESC'08, Rhodes, Greece, 15-19 June 2008; IEEE: New York, NY, USA, 2008; pp. 4202-4206.

43. Yu, W.; Lai, J.S.; Ma, H.; Zheng, C. High-efficiency dc-dc converter with twin bus for dimmable LED lighting. IEEE Trans. Power Electron. 2011, 26, 2095-2100. [CrossRef]

44. Lohaus, L.; Liao, L.; Strache, S.; Wunderlich, R.; Heinen, S. Energy efficient current control technique for driving high power LEDs. In Proceedings of the VDE PRIME'12, Aachen, Germany, 12-15 June 2012; pp. 1-4.

45. Li, S.N.; Zhong, W.X.; Chen, W.; Hui, S.Y.R. Novel self-configurable current-mirror techniques for reducing current imbalance in parallel light-emitting diode (LED) strings. IEEE Trans. Power Electron. 2012, 27, 2153-2162. [CrossRef]

46. Li, Y.C.; Chen, C.L. A novel primary-side regulation scheme for single-stage high-power-factor ac-dc LED driving circuit. IEEE Trans. Ind. Electron. 2013, 60, 4978-4986. [CrossRef]

47. Hwu, K.I.; Jenn, J.S.; Wen, Z.J. Interleaved boost converter with ZVT-ZCT for main switches and ZCS for auxiliary switch. Appl. Sci. 2019, 10, 2033. [CrossRef]

48. Erickson, R.W. Fundamentals of Power Electronics, 2nd ed.; Kluwer Academic Publishers: Norwell, MA, USA, 2001. 